Article

\title{
Electrophoretic Deposition of Graphene Oxide on Laser-Ablated Copper Mesh for Enhanced Oil/Water Separation
}

\author{
Rui Zhou ${ }^{1, * \mathbb{D}}$, Fei Shen ${ }^{1}$, Jingqin Cui ${ }^{2, *}$, Yonggang Zhang ${ }^{3}$, Huangping Yan ${ }^{1}$ and \\ Segovia Sanchez Juan Carlos 1 \\ 1 School of Aerospace Engineering, Xiamen University, 422 Siming South Road, Siming District, \\ Xiamen 361005, China; shenfei@stu.xmu.edu.cn (F.S.); hpyan@xmu.edu.cn (H.Y.); \\ 19920181156042@stu.xmu.edu.cn (S.S.J.C.) \\ 2 Pen-Tung Sah Institute of Micro-Nano Science and Technology, Xiamen University, Xiamen 361005, China \\ 3 AECC South Industry Company Limited, Zhuzhou 412002, China; dolphin0415@163.com \\ * Correspondence: rzhou2@xmu.edu.cn (R.Z.); jqcui@xmu.edu.cn (J.C.)
}

Received: 19 January 2019; Accepted: 25 February 2019; Published: 28 February 2019

check for updates

\begin{abstract}
The fabrication of bionic surfaces resembling hydrophobic plants through micro manufacturing, which creates abundant multi-level micro/nanostructures and elemental variations, has been widely employed to change the surface wettability of metallic materials. Based on the mechanisms for selective permeation of various liquids, it could achieve the function of oil/water separation. Herein, a separation copper membrane fabricated with pulsed laser ablation and modified with graphene oxide (GO) deposition showed a synergetic effect on tunable surface wettability. Micro/nanostructures were generated on the copper substrate membrane through concentric circular scanning, which was followed by hole drilling. Afterwards, charged GO nanosheets were deposited via electrophoresis. The spacing of circular lines, the diameter of the holes and the abundant high-surface-energy hydrophilic oxygen contained in deposited GO amounts could be regulated in the laser processing and deposition, resulting in oleophobicity and hydrophilicity at the same time. The highest contact angle of oil in water of the prepared mesh could reach above $165^{\circ}$ with a hole size of $200 \mu \mathrm{m}$ and a circular line spacing of $100 \mu \mathrm{m}$ after the laser processing. Water flux and oil-holding capacity, which represent the separation capability of the mesh, were also evaluated. The as-prepared separation mesh also showed great stability under harsh environments.
\end{abstract}

Keywords: oil/water separation; laser; graphene oxide; underwater superoleophobic; electrophoretic

\section{Introduction}

Environmental safety is increasingly being endangered by challenges such as oil spills and waste contamination. Novel oil treatment methods [1] based on surface wettability regulation have recently attracted researchers' interests. Inspired by the microstructures of animals and plants [2], such as the lotus leaf [3], biomimetic patterns are created on material surfaces aiming to change the Cassie (surfaces usually show extremely low adhesion to a liquid droplet) or Wenzel state (surfaces usually show very high adhesion to a liquid droplet) [4,5] of liquids on the surface, acquiring the capability of selective permeability, which is called a superhydrophobic/superoleophilic or a superhydrophilic/superoleophobic function, respectively [6-8]. The surface morphology and its chemical composition are of great importance to determine surface wettability [9-11]. In the separation mode, which is called the "oil removal" mode, oil-removal materials create a barrier between oil and water. The oil droplets easily pass through the barrier but the water phase remains above the separation membranes due to the superhydrophobicity. In 2004, Jiang et al. [12] successfully fabricated 
a mesh with both superhydrophobic and superoleophilic properties through coating stainless-steel mesh with a homogeneous emulsion containing low-surface-energy polytetrafluoroethylene (PTFE). With this PTFE-coated mesh, oil/water mixtures were separated successfully. Another method, called the "water removal" method, has been widely studied by depositing hydrophilic coating materials such as calcium carbonate $\left(\mathrm{CaCO}_{3}\right)$, silica or zinc oxide $(\mathrm{ZnO})$ onto a surface. Palygorskite as a type of porous material has rich micro/nanostructures on its surface. In 2015, Jian et al. [13] employed palygorskite powders and waterborne polyurethane (PU) mixtures as a coating sprayed on copper mesh, which exhibited excellent underwater superoleophobicity. In 2017, Huo et al. [14] demonstrated a simple fabrication method to achieve an underwater superoleophobic glass surface with tunable oil adhesion by controlling the area ratio of the untreated flat glass region to the laser-ablated rough region. This property of adjustable adhesion of oil could play as a "mechanical hand" in actual applications, such as no-loss transactions. Though the research has covered many aspects of surface wettability so far [15-17], the modification of surface wettability involving graphene oxide (GO) on laser-ablated copper mesh is rarely reported. As an oxidized graphene-based product, GO is a type of hydrophilic material with hierarchical structures and abundant oxygen-containing groups [18-20], providing the possibility of specific applications by enhancing the liquid surface wettability, such as oil/water separation. In 2015, Huang et al. [21] prepared a novel GO ultrafiltration membrane by distributing GO nanosheets into polyamide supports. This membrane exhibits strong cyclic oil/water separation capability with high anti-fouling performance. However, the materials they used were restricted to polymers with poor mechanical durability. GO coating combined with traditional metal meshes also have been reported for anti-corrosion and oil/water separation applications [22-24]. Compared to other GO coating or hybrid methods, the electrophoresis process is simple and convenient, needing only a DC power. Also, it has been found that GO coating by electrophoresis usually requires only several seconds. This paper investigates the separation capability of metal meshes coated with electrophoretically deposited GO.

Herein, oil/water separation copper meshes were fabricated by pulsed nanosecond laser ablation followed by the electrophoretic deposition of GO nanosheets, as shown in Figure 1. Circular lines were carved and through-holes were drilled, changing the overall morphology of the copper substrate and rendering it hydrophilic by generating plenty of nanoparticles. The abundant hydrophilic functional groups of the deposited GO contributed to the high surface energy on the copper mesh, which gained enhanced superhydrophilicity (in air) and superolephobicity (underwater). The circular lines connected to the holes guided the movement of water droplets towards the holes where they passed through, achieving oil/water separation. The contact angle of oil droplets was well above $150^{\circ}$ for the as-prepared mesh immersed in water. Meanwhile, water droplets could spread into the mesh instantly after being dropped onto the surface, passing through the holes effortlessly. The separation efficiency was above $95 \%$ even after cyclic rinsing. The as-prepared GO-modified copper mesh showed high separation efficiency and impressive durability in harsh environments, suggesting promising applications in oil pollution treatment. 


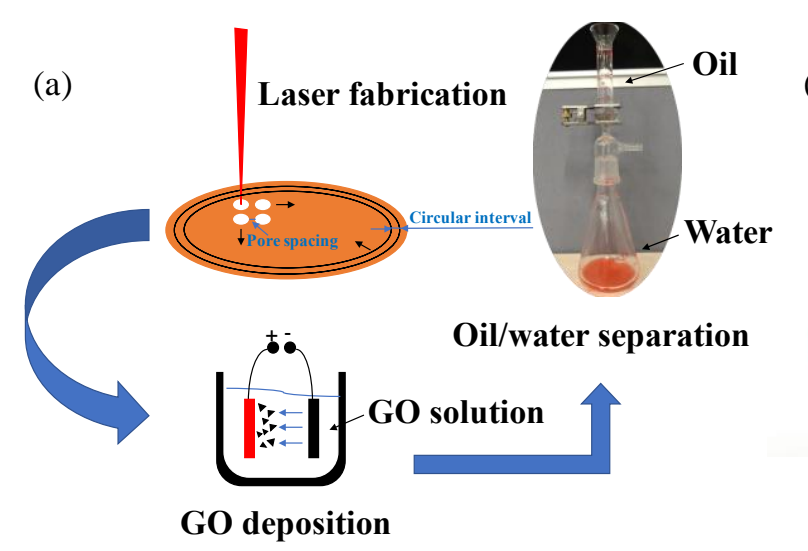

(b)

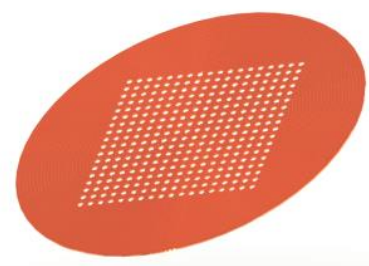

Figure 1. (a) Schematic diagram of the fabrication of the copper mesh and the oil/water separation process; (b) detailed diagram of the copper mesh fabricated by pulsed laser ablation.

\section{Materials and Methods}

\subsection{Laser Nanostructuring of Copper Sheet}

A commercially available circular copper plate $(99.99 \%$ purity) with a diameter of $30 \mathrm{~mm}$ and a thickness of $0.1 \mathrm{~mm}$ was used as the substrate for the laser processing. The laser source was a 1064-nm IPG:YLP fiber laser operating in a pulse mode with an effective pulse duration of $100 \mathrm{~ns}$. The scanning speed, average laser power and repetition frequency were set at $500 \mathrm{~nm} / \mathrm{s}, 80 \mathrm{~W}$ and $20 \mathrm{kHz}$ during the process. The spot size of the laser was $0.05 \mathrm{~mm}$. Firstly, seven concentric circular lines were carved on the copper plate using the contour scan mode starting from the edge. The interval of the concentric circles was set as 100, 200 or $300 \mu \mathrm{m}$. The most-outer ring had a fixed diameter of $22 \mathrm{~mm}$. Then, an array of cylindrical through-holes was drilled over an area of $10 \mathrm{~mm} \times 10 \mathrm{~mm}$ in the central region of the plate (Figure 1b). In the fabrication process of holes, the laser scanning path was restricted in a small circle with crossing Hatch Scan lines, which was usually repeated 40 times until the copper plate was pierced through. The hole-spacing, i.e., the shortest distance between edges of two adjacent holes, was fixed at $300 \mu \mathrm{m}$ regardless the diameters of holes. The tested diameters of holes were 150, 200, 250, $300,350,400,450$ and $500 \mu \mathrm{m}$. All the scanning electron microscopy (SEM) images of this paper were taken with a ZEISS SUPRA 55 (Carl Zeiss, Jena, Germany) and the applied acceleration voltage was $10 \mathrm{kV}$.

\subsection{Graphene Oxide Deposition}

The electrophoresis method was applied to deposit GO on the fabricated copper mesh. The GO aqueous dispersion (Institute of Coal Chemistry, Chinese Academy of Sciences) (Taiyuan, China) was diluted with DI water to be 2,3 or $4 \mathrm{mg} / \mathrm{mL}$. The deposition time lasted from 5 to $25 \mathrm{~s}$ with an interval of $5 \mathrm{~s}$. The to-be-deposited copper mesh serving as the positive electrode and a reference copper plate serving as the negative electrode were immersed in the GO dispersion with a fixed distance of $10 \mathrm{~mm}$. Upon applying a 10-V DC potential, GO particles were deposited on the copper mesh as they carried negative charges. The concentration of GO dispersion and the deposition time were tuned to control the amount of GO deposited on the mesh. Both before and after electrophoretic deposition, the copper meshes were vacuum-dried at room temperature overnight. The mass difference of an as-prepared mesh before and after the GO deposition was weighed by an electronic balance for the purpose of calculating the amount of deposited GO. Energy dispersive spectrometry (EDS) was performed to understand the surface chemistry of the GO-deposited copper meshes.

\subsection{Contact Angle Measurement}

The underwater oil contact angle (OCA) was measured for a copper mesh immersed in water with a DSA-25 drop shape analyzer (KRUSS, Hamburg, Germany). The copper mesh was fixed in water 
with two sets of metal bars (detailed in Figure 3a,b). Then, $2.0 \mu \mathrm{L}$ of kerosene oil (Aladdin Reagent, Shanghai, China) was added beneath the copper mesh with a dosing system precisely controlled by the analyzer. A high-quality image was then recorded and the contact angle of the oil droplet could be analyzed. The OCA of each sample was measured three times, which were averaged to evaluate the OCAs of the as-prepared samples more accurately.

\subsection{Oil/Water Separation and Durability}

Firstly, $30 \mathrm{~mL}$ kerosene and $30 \mathrm{~mL}$ water were directly mixed in a beaker. Three droplets of Cromophtal Red 214 (BASF) were added into the mixture to visually distinguish the oil phase and water phase, which were originally both transparent and colorless. As the pigment is hydrophilic, water in the mixture could be fully dyed. The mixture was poured on top of the copper mesh, which was fixed in the center of the separation device as shown in Figure 1. The oil with a density lower than water naturally floated above the water phase before the separation experiment. For the anti-corrosion test, the copper mesh was immersed in an aqueous solution of hydrochloric acid at $\mathrm{pH}=1$ for a fixed duration, which was followed by rinsing with DI water. Then the underwater OCA of the treated copper mesh was measured. For the adhesion durability test, the as-prepared copper mesh was flushed for $3 \mathrm{~min}$ under a water flux above $2 \times 10^{6} \mathrm{~L} / \mathrm{m}^{2} \mathrm{~h}$ before the oil/water separation process.

\section{Results and Discussion}

\subsection{Laser-Ablated Copper Mesh without GO Deposition}

The morphologies of the copper mesh fabricated by laser nanostructuring described in Section 2.1 are shown in Figure 2. After the laser ablation, the initial smooth surface between the concentric scan lines was randomly and ubiquity covered with micro/nanoparticles deposited in various sizes. All through-holes in Figure 2 looked like "caldera" with piles of particles around them. Obviously, concentric circular lines carved on the copper greatly enriched the micro/nanostructures of surfaces (Figure $2 b$ ) compared to untreated surfaces with only an array of holes (Figure 2a).

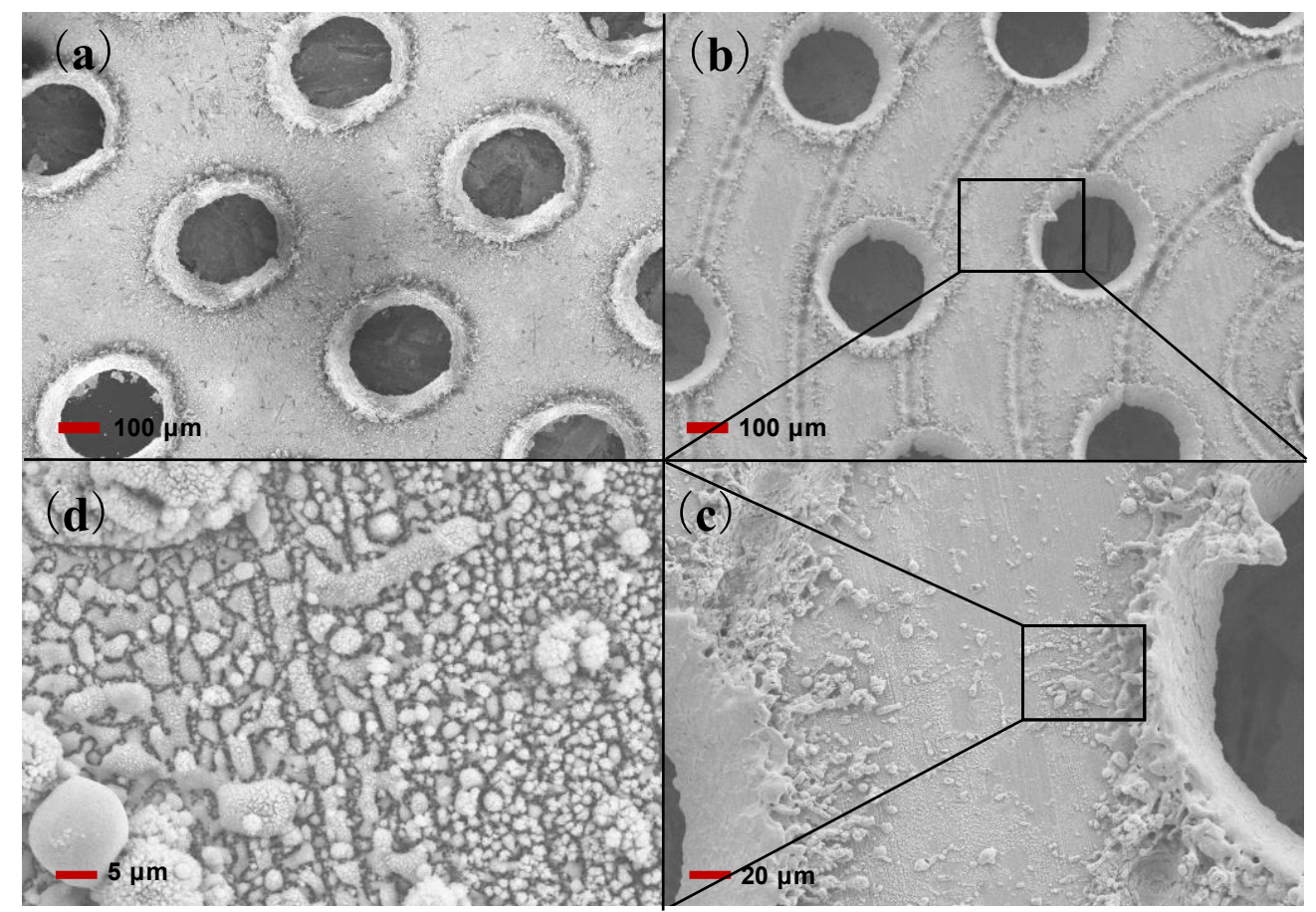

Figure 2. SEM images of the copper mesh after the laser ablation: (a) copper surface with ablated holes only; (b) copper surface with circular lines and holes; (c) surface morphology between two holes; and (d) the magnified area of (c) with micro/nanostructures. 
Pulsed laser ablation has become a popular processing tool for micro/nanostructures due to its precision and efficiency. When the laser irradiates a substrate, its energy is absorbed by the surface material resulting in a heat-affected zone. If the laser light intensity is below the vaporization threshold of the irradiated surface, it leads to a temperature rise of the surface and does not produce significant morphology change. However, if the laser light intensity is above the vaporization threshold, melting and vaporization take place on the surface substrate [25-27]. Then the evaporated materials redeposit in the form of micro/nanoparticles, creating desired structures on the surface. As observed in Figure 2, in the fabrication process of this experiment, if the energy of laser ablation exceeds the vaporization threshold of $\mathrm{Cu}$, the $\mathrm{Cu}$ particles sputtered and some of them reacted with $\mathrm{O}_{2}$ in air to generate $\mathrm{CuO}$ or $\mathrm{Cu}_{2} \mathrm{O}$ particles [28]. Then the re-deposition process occurs, forming the desired structures.

The kind of nanostructured surface shown in Figure 2, when casted with liquid drops in air, transformed a would-be solid-liquid contact line into a solid-liquid-air three-phase contact line as the numerous gaps between the micro/nanoparticles produced tiny air pockets and prevented liquid from entering. This phenomenon, described by the classic Cassie-Baxter infiltration model, blocks liquid from fully wetting the surface and achieves a state of hydrophobicity [29]. Similarly, for a rough surface with a high surface energy in water, water molecules can easily enter the gaps between the micro/nanostructures, forming a water film which efficiently blocks oil molecules from entering the gaps and achieves a function of underwater oleophobicity over the rough surface [30]. Due to the natural incompatibility of water and oil, this results in a small contact area between the oil droplets and copper mesh surface in a water environment to achieve the function of underwater oleophobicity.

To determine the underwater oil contact angle (OCA), the fabricated copper mesh was stabilized in water as shown in Figure $3 a, b$. The contact angle was measured from a magnified image of the oil droplet (Figure 3c). Samples with various concentric line separations and hole sizes were stuied. In Figure $3 \mathrm{~d}$, the OCAs of all samples are above $150^{\circ}$, exhibiting excellent underwater superoleophobicity. Also, the OCAs of the meshes with $0.2 \mathrm{~mm}$ concentric line spacing are much higher than the samples with 0.1 and $0.3 \mathrm{~mm}$ spacing. But how do concentric line spacing and hole size distribution affect the surface structure and wettability? The sputtered particles mainly distribute along the ablation line. If the spacing is too large, a majority of the copper surface will not be covered with noticeable micro/nanostructures accessible to the oil. While for small spaces such as $0.1 \mathrm{~mm}$, initially the particles can distribute uniformly in the space between two adjacent lines after the first laser ablation, but these particles may be ablated away in the subsequent carving due to thermal accumulation as the heat effect is much more obvious in a smaller interval area. The optimized interval of $0.2 \mathrm{~mm}$ was chosen for the following experiments.

The separation capability of a fabricated copper mesh was defined with the water flux which represents the separating speed, and the maximum volume of oil $(\mathrm{mL})$ that the copper mesh could hold, which represents the separation ability [31]. The water flux (F) was calculated using the following formula [32]:

$$
F=\frac{V}{S * t}
$$

where $V$ is the total volume of water that permeates through the copper mesh, $S$ is the cross-section area of the mesh and $t$ is the time required for the water to pass through.

The water flux gradually increased for meshes with hole diameters from 0.15 to $0.5 \mathrm{~mm}$, as seen in Figure 3e. Larger holes apparently provided wider tunnels for water to pass through. In contrast, the maximum amount of oil retained showed a decreasing trend with the increase of the hole size. In the $y$-direction, the oil body was balanced with the downward intrusion force, gravity and the supporting force from the surface. A mesh with larger holes led to a smaller surface, resulting in less oil supported over the mesh, hence the trend shown in Figure 3f. Once the total volume of liquids reached beyond the threshold, the force balance crashed and all liquid passed through the mesh. 


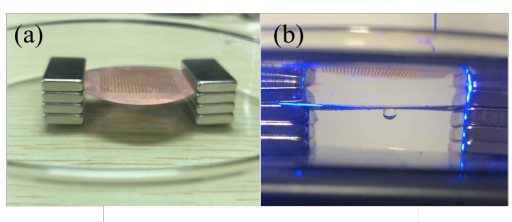

(c)

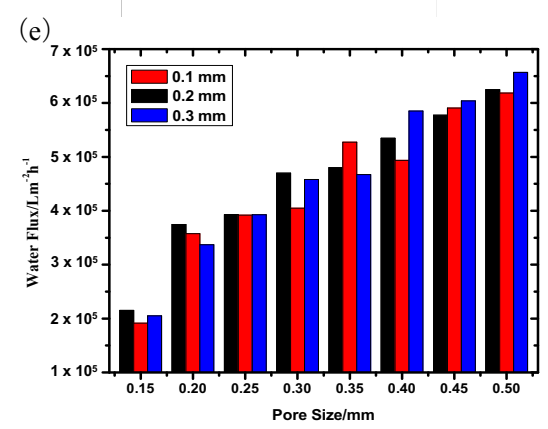

(g)

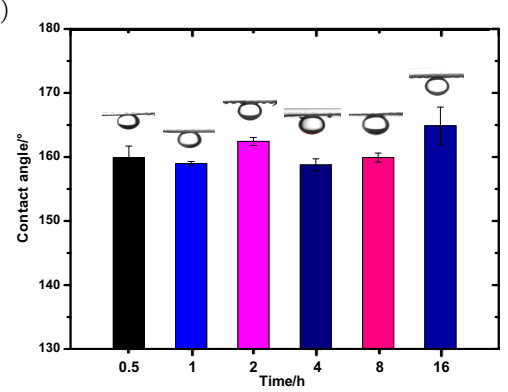

(d)

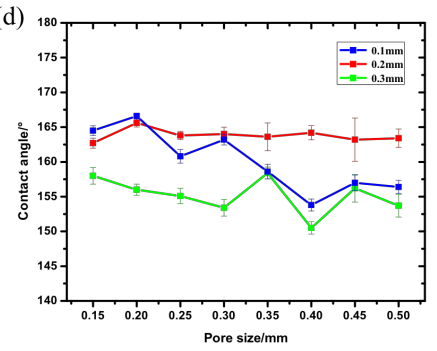

(f)

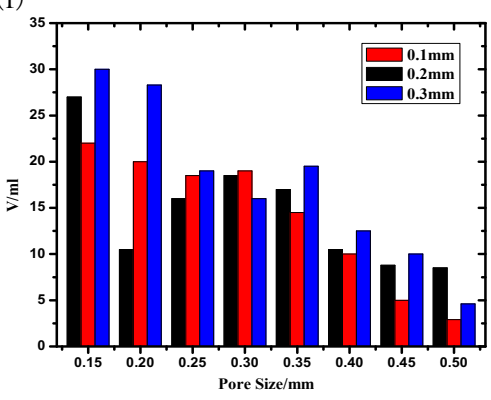

(h)

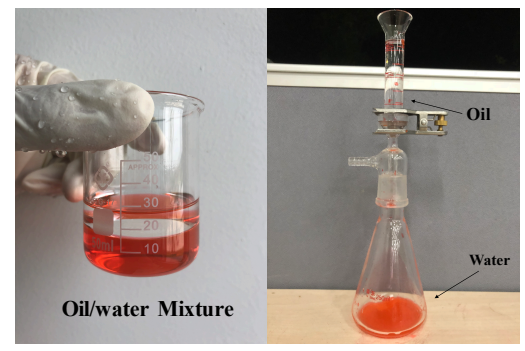

Figure 3. (a,b) Experimental setup of underwater oil contact angle (OCA) test; (c) contact angle of an oil droplet at the surface of $\mathrm{Cu}$ mesh immersed in water; (d) OCA of $\mathrm{Cu}$ meshes with different hole sizes from 0.15 to $0.5 \mathrm{~mm}$ and different scanning intervals of concentric lines; (e) test of water flux and (f) maximum oil-holding volumes of the meshes; (g) underwater OCA of samples with a $0.3 \mathrm{~mm}$ hole size and $0.2 \mathrm{~mm}$ concentric line spacing after immersion in strong acid for different durations;

(h) oil/water separation setup.

To test the separator's stability in practical applications facing all kinds of environmental challenges, the meshes were put into a corrosive acid solution of $\mathrm{pH}=1$. The samples were kept in the acid for $0.5,1,2,4,8$ and $16 \mathrm{~h}$, and OCAs were tested. All samples maintained excellent superolepobicity, as observed in Figure $3 g$, indicating excellent corrosion resistance. After corrosion for $16 \mathrm{~h}$, the mesh even exhibited a slightly larger OCA than the original contact angle. The possible reason for this is that the acid produced more nanostructures over the copper mesh and made the surface even rougher [33].

Figure $3 \mathrm{~h}$ shows the experimental setup for the oil/water separation experiment. This fabricated copper mesh exhibited excellent oleophobicity/hydrophilicity, which could be used to separate an oil/water mixture by the "water removal" method to achieve the goal of successful separation. The fabricated copper mesh was set in the middle of the separation device. After pouring into the upper glass tube, the water infiltrated rapidly while the kerosene stayed above the mesh. With excellent oleophobicity/hydrophilicity, the mesh allowed water to pass through the holes easily, resulting in efficient oil/water separation. 


\subsection{Electrophoretic Deposition of GO on the Laser-Ablated Copper Mesh}

Electrophoresis drives the movement of charged GO nanosheets under the action of an external electric field. The surface morphologies of GO-deposited copper meshes with the concentrations of 2,3 and $4 \mathrm{mg} / \mathrm{mL}$ for $10 \mathrm{~s}$ are compared in Figure 4 . It can be seen that, compared to the pristine mesh, the surfaces coated with GO appear smoother. As shown in Figure 5, EDS verified the existence of both carbon and oxygen elements for coated areas. The atomic ratio of O:Cu for the ablated $\mathrm{Cu}$ mesh was roughly 30:70, where oxygen originated from the process of laser nanostructuring. After electrophoresis, the atomic ratio changed to 35:14:51 (O:Cu:C), suggesting uniform GO thin film modification on the copper surface (Figure $5 a$ and insets). In Figure $5 b$, the $C$ and $O$ elements overlap in the $\mathrm{Cu}$ mesh cross-section image, while $\mathrm{Cu}$ was mostly detected in the exposed cross-sections, further proving the successful deposition of GO. Semi-transparent and flexible GO sheets can be seen in the SEM image. In Figure 4, area 1 shows abundant micro/nanostructures from laser ablation. When deposited with GO, the surfaces were gradually filled up with GO flakes and became flatter. Higher GO concentration (from 2 to $4 \mathrm{mg} / \mathrm{mL}$ ) produced an even smoother layer of translucent film (Figure $4 \mathrm{f}, \mathrm{i}, \mathrm{j}$ ), covering many of the surface microstructures. The morphologies confirmed that GO films from different concentrations produced assorted surface roughness levels and hence the diverse OCAs in Figure 6.

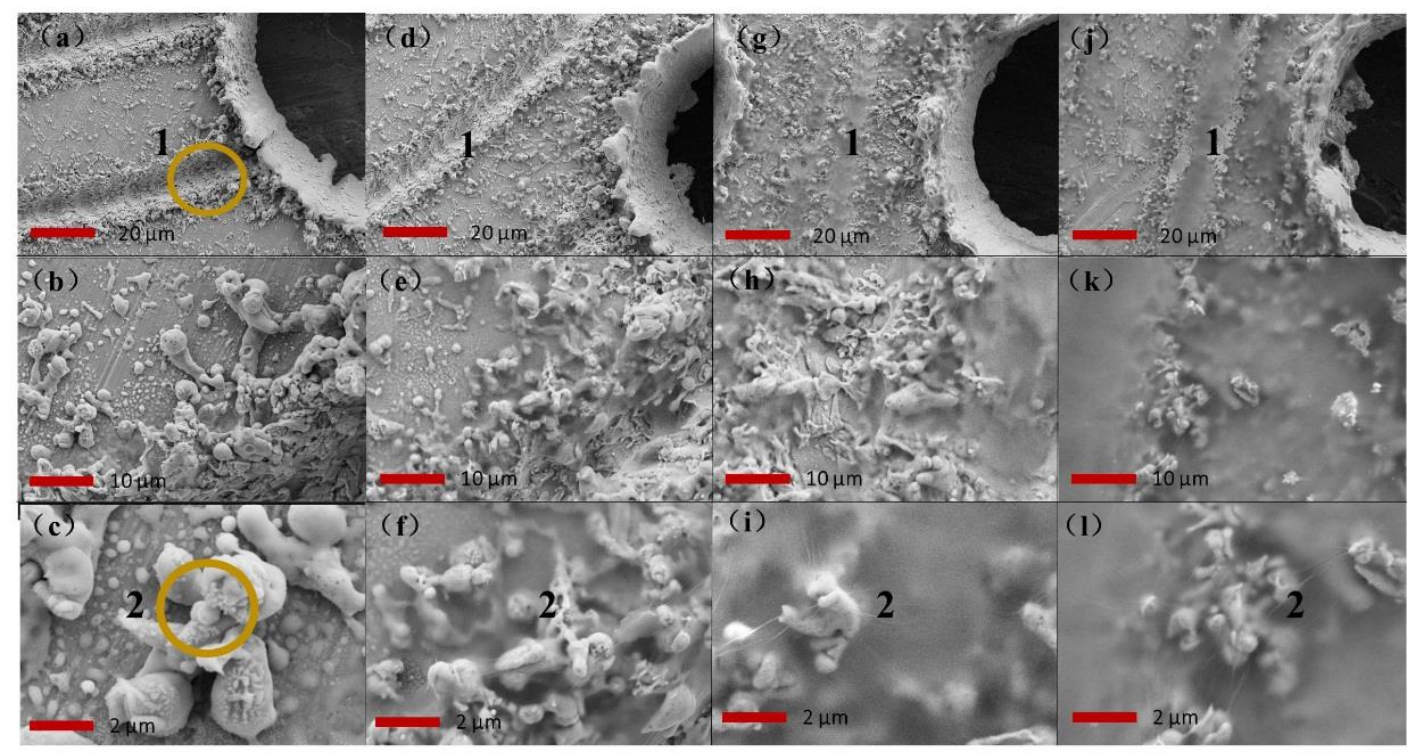

Figure 4. SEM images of samples with a $0.3 \mathrm{~mm}$ hole size and $0.2 \mathrm{~mm}$ concentric line spacing, (a-c) no GO coating; (d-f) $2 \mathrm{mg} / \mathrm{mL}$ GO liquid concentration and $10 \mathrm{~s}$ deposition time; (g-i) $3 \mathrm{mg} / \mathrm{mL}$ GO liquid concentration and $10 \mathrm{~s}$ deposition time; $(\mathbf{j}-1) 4 \mathrm{mg} / \mathrm{mL}$ GO liquid concentration and $10 \mathrm{~s}$ deposition time.

Modifying the copper surface with graphene oxide affects its liquid wettability because the functional groups of GO are mostly hydrophilic. The amount of GO deposited is influenced by both GO dispersion concentration and depositing time. In Figure 6, the OCA of modified meshes noticeably decreased with the increasing GO concentration. For meshes deposited in the $4 \mathrm{mg} / \mathrm{mL}$ dispersion, only the $5 \mathrm{~s}$ sample maintained an OCA higher than $150^{\circ}$, while samples deposited longer than $5 \mathrm{~s}$ all lost their underwater superolephobicity. For these samples, the thick GO layer most probably covered their surface micro/nanostructures, created a smoother surface and caused the OCA to shift from superoleophobic to oleophobic states. Compared to the GO concentration, the deposition time had less effect on the OCA changes as the variation of OCA was less than $5^{\circ}$ for most samples. 

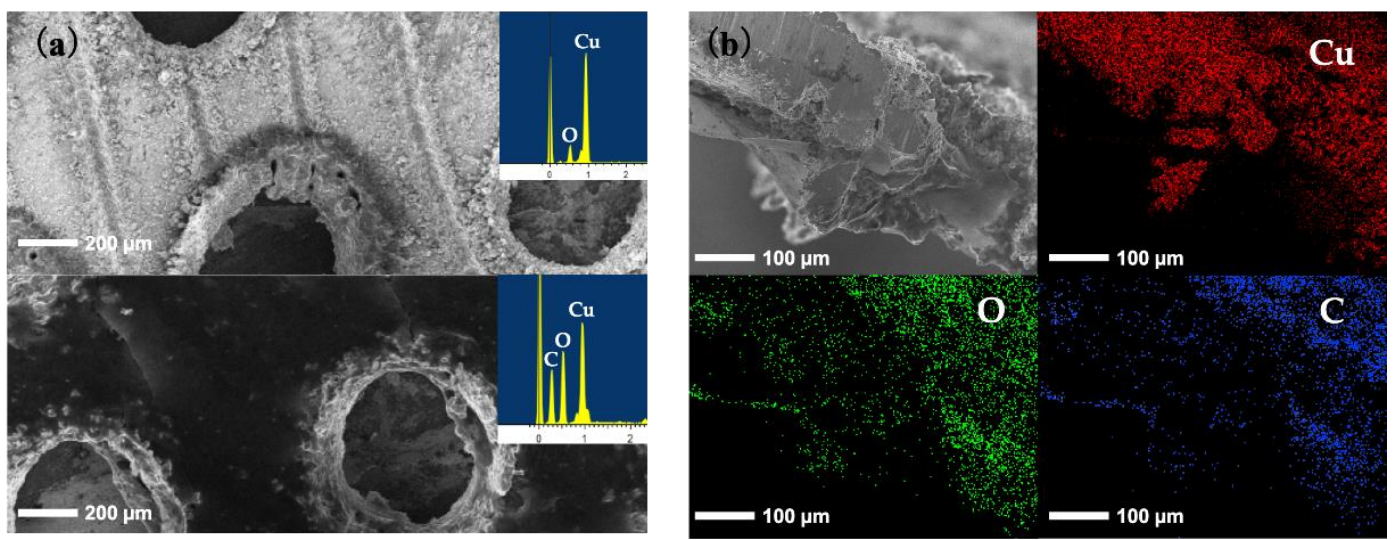

Figure 5. SEM images of the $\mathrm{Cu}$ mesh and EDS analysis. (a) SEM images of $\mathrm{Cu}$ mesh before (top) and after (bottom) GO deposition and the relative energy dispersive spectrometry (EDS) peaks; (b) SEM image and elemental maps of the cross-section view of $\mathrm{Cu}$ mesh after GO deposition.

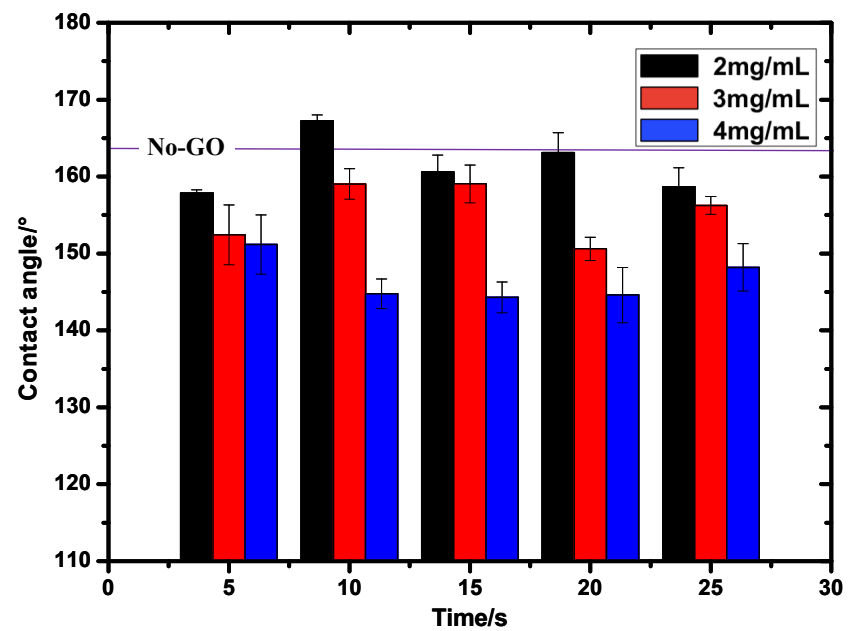

Figure 6. Contact angle of samples with different deposition times and different GO solution concentrations.

Table 1 summarizes the amount of GO deposited on copper meshes under different experimental conditions and the numbers indicate that the deposition did not reach its saturation point; therefore, the OCA variation was mainly caused by a combined effect of the substrate roughness and GO modification. Impressively, the OCA of the copper mesh modified in $2 \mathrm{mg} / \mathrm{mL}$ GO for $10 \mathrm{~s}$ reached $168^{\circ}$, which was higher than the best non-GO sample tested $(0.3 \mathrm{~mm}$ hole size, $0.2 \mathrm{~mm}$ spacing, violet line). The reason for this is that the sputtering effect during the laser processing cannot fully cover the copper surface, and there are probably some areas with insufficient micro/nanostructures for an oil droplet to maintain a stable Cassie-Baxter state. The appropriate amount of GO coating creates considerate nanostructures over these areas, and also improves the roughness of other areas at the same time. GO deposition successfully enhances the underwater superoleophobicity.

Table 1. Weight of deposition amount of GO on the mesh surface after the electrophoretic method.

\begin{tabular}{cccccc}
\hline Concentration & $\mathbf{5 s}$ & $\mathbf{1 0 ~ s}$ & $\mathbf{1 5 s}$ & $\mathbf{2 0 ~ s}$ & $\mathbf{2 5 \mathrm { s }}$ \\
\hline $2 \mathrm{~g} / \mathrm{L}$ & $1 \mathrm{mg}$ & $3 \mathrm{mg}$ & $21 \mathrm{mg}$ & $64 \mathrm{mg}$ & $71 \mathrm{mg}$ \\
$3 \mathrm{~g} / \mathrm{L}$ & $5 \mathrm{mg}$ & $46 \mathrm{mg}$ & $143 \mathrm{mg}$ & $158 \mathrm{mg}$ & $220 \mathrm{mg}$ \\
$4 \mathrm{~g} / \mathrm{L}$ & $3 \mathrm{mg}$ & $54 \mathrm{mg}$ & $128 \mathrm{mg}$ & $157 \mathrm{mg}$ & $155 \mathrm{mg}$ \\
\hline
\end{tabular}


The deposition amount, which is determined by the deposition time and the concentration of $\mathrm{GO}$, has a vital effect on the performance of the OCA. The right amount of GO modification revises the un-ablated areas, improving the overall surface roughness and leading to the increase of the contact angle. However, if the GO film is excessively thick to cover the micro/nanostructures on the surface, the surface roughness and the OCA decrease dramatically. Hence, the appropriate amount of GO deposition alternates the roughness of un-ablated areas, leading to the overall increase of the underwater OCA. Otherwise, if the GO is excessively abundant to cover the micro/nanostructures on the surface, the roughness decreases and so does the OCA.

The water flux and the maximum volume of oil held by the GO-modified mesh were also tested, as shown in Figure 7. Compared to the non-GO-coated sample indicated by the lines in the plots, both the water flux and the maximum volume of oil retained above the mesh (holding volume) showed enhancements for some samples. Especially for samples coated in $4 \mathrm{mg} / \mathrm{mL} \mathrm{GO}$ dispersion, the thick film on the mesh surface randomly blocked partial pores as observed in Figure 4, resulting in a huge improvement of its oil-holding capability.
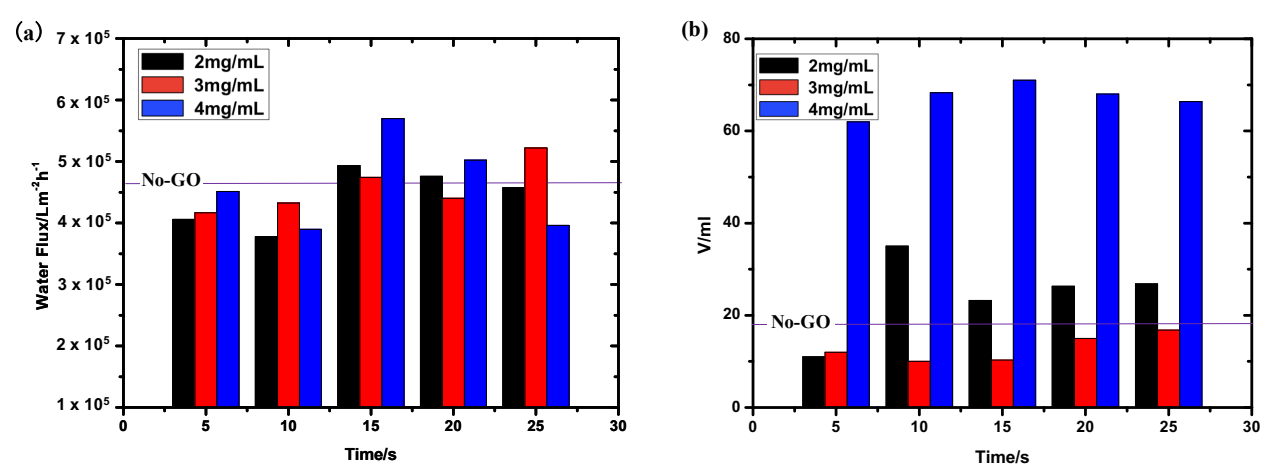

Figure 7. Change of (a) water flux and (b) maximum oil-holding capacity of GO-coated samples. Electrophoresis deposition was carried out in 2, 3 or $4 \mathrm{mg} / \mathrm{mL} \mathrm{GO}$ dispersions for 5, 10, 15, 20 or $25 \mathrm{~s}$.

The systematic tests showed that the copper mesh ablated by the laser with a $0.3 \mathrm{~mm}$ hole size, $0.2 \mathrm{~mm}$ concentric line spacing, and modified in $2 \mathrm{mg} / \mathrm{mL}$ GO dispersion for $10 \mathrm{~s}$ exhibited excellent separation speed and a good performance concerning water flux and oil-holding capacity. This specific sample was further characterized in a corrosive (acidic) environment and under water flushing to verify the stability of the surface micro/nanostructures and the adhesion of the GO deposition on copper mesh, respectively. Results of the corrosion experiment and the cyclic flushing experiment are shown in Figure 8. After immersing the mesh into a $\mathrm{pH}=1$ acid solution for $4 \mathrm{~h}$, the mesh OCA could still maintain over $130^{\circ}$, as shown in Figure 8a. When it was treated for 8 or $16 \mathrm{~h}$, the mesh lost its oleophobicity with the OCA dramatically decreasing to $115^{\circ}$ and $80^{\circ}$, respectively, which may be attributed to the weakened adhesion between the GO coating film and the copper surface after soaking for a long time. Some areas of the GO film partially detached from the copper surface, leading to the smoothing of the rough surface that was originally tightly wrapped by the GO film by tuning the surface wettability. The adhesion durability test showed that the recovered separation efficiency was well above $98 \%$ for the first five cycles, but upon further cyclic flushing the binding force between the GO film and copper surface was significantly weakened, the GO film fell off as a whole and the mesh eventually lost its separation ability. 

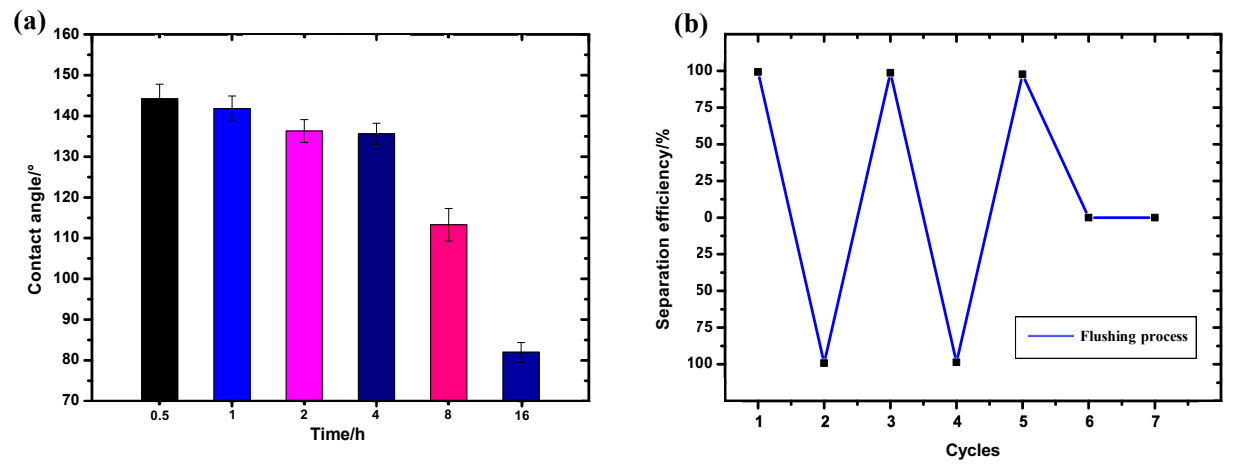

Figure 8. (a) Underwater oil contact angle of GO-coated copper meshes after immersion in $\mathrm{pH}=1 \mathrm{HCl}$ acid for different times; (b) recovered separation efficiency after cyclic flushing.

\section{Conclusions}

In summary, an oil/water separation membrane made of copper and GO with underwater superoleophobicity was fabricated. The membrane, composed of an array of circular holes and concentric lines constructed by laser ablation, possessed superoleophobicity in water. Deposited with a layer of hydrophibic GO film using the electrophoresis process, the mesh obtained an enhanced oil/water separation capability. The changes of surface morphologies after GO coating were investigated along with the variation of the ablation conditions and electrophoresis parameters. The fabricated copper meshes proved to have excellent acid resistance and strong adhesion durability after being extensively treated with strong acid or running water. The proposed separation membrane fabrication technique, combining laser ablation and thin film modification, will have promising applications in fields such as oil recovery, wastewater treatment and water purification.

Author Contributions: Conceptualization, R.Z. and F.S.; Data curation, F.S. and S.S.J.C.; Formal analysis, R.Z., F.S., J.C. and Y.Z.; Funding acquisition, R.Z.; Investigation, F.S., H.Y. and S.S.J.C.; Methodology, F.S.; Project administration, R.Z.; Resources, R.Z. and H.Y.; Software, F.S.; Supervision, R.Z. and J.C.; Validation, R.Z., F.S. and J.C.; Visualization, F.S.; Writing—original draft, F.S.; Writing—review and editing, R.Z. and J.C.

Funding: This research was funded by the National Natural Science Foundation of China under Grant No. 61605162, the Natural Science Foundation of Fujian Province of China under Grant No. 2017J05106 and the Ministry of Education of China under Grant No. CXZJHZ201738.

Acknowledgments: Collaborative Innovation Center of High-End Equipment Manufacturing in Fujian.

Conflicts of Interest: The authors declare no conflict of interest. The funders had no role in the design of the study; in the collection, analyses, or interpretation of data; in the writing of the manuscript, or in the decision to publish the results.

\section{References}

1. Zhang, W.; Shi, Z.; Zhang, F.; Liu, X.; Jin, J.; Jiang, L. Superhydrophobic and Superoleophilic PVDF Membranes for Effective Separation of Water-in-Oil Emulsions with High Flux. Adv. Mater. 2013, 25, 2071-2076. [CrossRef] [PubMed]

2. Yong, J.; Chen, F.; Fang, Y.; Huo, J.; Yang, Q.; Zhang, J.; Bian, H.; Hou, X. Bioinspired Design of Underwater Superaerophobic and Superaerophilic Surfaces by Femtosecond Laser Ablation for Anti- or Capturing Bubbles. ACS Appl. Mater. Interfaces 2017, 9, 39863-39871. [CrossRef] [PubMed]

3. Marmur, A. The Lotus effect: Superhydrophobicity and metastability. Langmuir 2004, 20, 3517-3519. [CrossRef] [PubMed]

4. Cassie, A.B.D.; Baxter, S. Wettability of porous surfaces. Trans. Faraday Soc. 1944, 40, 546-551. [CrossRef]

5. Wenzel, R.N. Resistance of Solid Surfaces to Wetting by Water. Ind. Eng. Chem. 1936, 28, 988-994. [CrossRef]

6. Xue, Z.; Wang, S.; Lin, L.; Chen, L.; Liu, M.; Feng, L.; Jiang, L. A novel superhydrophilic and underwater superoleophobic hydrogel-coated mesh for oil/water separation. Adv. Mater. 2011, 23, 4270-4273. [CrossRef] [PubMed] 
7. Zhang, F.; Zhang, W.B.; Shi, Z.; Wang, D.; Jin, J.; Jiang, L. Nanowire-haired inorganic membranes with superhydrophilicity and underwater ultralow adhesive superoleophobicity for high-efficiency oil/water separation. Adv. Mater. 2013, 25, 4192-4198. [CrossRef] [PubMed]

8. Yong, J.; Chen, F.; Yang, Q.; Bian, H.; Du, G.; Shan, C.; Huo, J.; Fang, Y.; Hou, X. Oil-Water Separation: A Gift from the Desert. Adv. Mater. Int. 2016, 3, 1500650-1500656. [CrossRef]

9. Kwon, G.; Kota, A.K.; Li, Y.; Sohani, A.; Mabry, J.M.; Tuteja, A. On-Demand Separation of Oil-Water Mixtures. Adv. Mater. 2012, 24, 3666-3671. [CrossRef] [PubMed]

10. Long, Y.; Hui, J.-F.; Wang, P.-P.; Xiang, G.-L.; Xu, B.; Hu, S.; Zhu, W.-C.; Lü, X.-Q.; Zhuang, J.; Wang, X. Hydrogen Bond Nanoscale Networks Showing Switchable Transport Performance. Sci. Rep. 2012, 2, 612-617. [CrossRef] [PubMed]

11. Lee, C.H.; Johnson, N.; Drelich, J.; Yap, Y.K. The performance of superhydrophobic and superoleophilic carbon nanotube meshes in water-oil filtration. Carbon 2011, 49, 669-676. [CrossRef]

12. Feng, L.; Zhang, Z.; Mai, Z.; Ma, Y.; Liu, B.; Jiang, L.; Zhu, D. A super-hydrophobic and super-oleophilic coating mesh film for the separation of oil and water. Angew. Chem. 2004, 43, 2012-2014. [CrossRef] [PubMed]

13. Li, J.; Yan, L.; Li, H.; Li, W.; Zha, F.; Lei, Z.Q. Underwater superoleophobic palygorskite coated meshes for efficient oil/water separation. J. Mater. Chem. 2015, 3, 14696-14702. [CrossRef]

14. Huo, J.; Yang, Q.; Feng, C.; Yong, J.; Yao, F.; Zhang, J.; Lin, L.; Xun, H. Underwater transparent miniature "mechanical hand" based on femtosecond laser-induced controllable oil-adhesive patterned glass for oil droplet manipulation. Langmuir 2017, 33, 3659-3665. [CrossRef] [PubMed]

15. Li, J.; Guan, P.; Zhang, Y.; Xiang, B.; Tang, X.; She, H. A diatomite coated mesh with switchable wettability for on-demand oil/water separation and methylene blue adsorption. Sep. Sci. Technol. 2017, 174, 275-281. [CrossRef]

16. Lo, Y.-H.; Yang, C.-Y.; Chang, H.-K.; Hung, W.-C.; Chen, P.-Y. Bioinspired Diatomite Membrane with Selective Superwettability for Oil/Water Separation. Sci. Rep. 2017, 7, 13422-13429. [CrossRef] [PubMed]

17. Yan, H.; Rashid, M.R.B.A.; Si, Y.K.; Li, F.; Hong, M. Wettability Transition of Laser Textured Brass Surfaces inside Different Mediums. Appl. Surf. Sci. 2017, 369-375. [CrossRef]

18. Wang, G.; Wang, B.; Park, J.; Yang, J.; Shen, X.; Yao, J. Synthesis of enhanced hydrophilic and hydrophobic graphene oxide nanosheets by a solvothermal method. Carbon 2009, 47, 68-72. [CrossRef]

19. Wei, N.; Lv, C.; Xu, Z. Wetting of Graphene Oxide: A Molecular Dynamics Study. Langmuir 2014, 30, 3572-3578. [CrossRef] [PubMed]

20. Guiyuan, C.; Xiaosong, G.; Han, L.; Baohua, J. An accurate design of graphene oxide ultrathin flat lens based on Rayleigh-Sommerfeld theory. Opto. Electron. Adv. 2018, 1, 180012. [CrossRef]

21. Huang, Y.; Li, H.; Wang, L.; Qiao, Y.; Tang, C.; Jung, C.; Yoon, Y.; Li, S.; Yu, M. Ultrafiltration Membranes with Structure-Optimized Graphene-Oxide Coatings for Antifouling Oil/Water Separation. Adv. Mater. Int. 2015, 2, 1400433-1400439. [CrossRef]

22. Xu, Y.; Li, J.; Huang, W. Porous Graphene Oxide Prepared on Nickel Foam by Electrophoretic Deposition and Thermal Reduction as High-Performance Supercapacitor Electrodes. Materials 2017, 10, 936.

23. Saba, N.; Chang-Mou, W.; Ting-Zhen, X.; Chiu-Chun, L.; Syang-Peng, R. Oil-Water Separation of Electrospun Cellulose Triacetate Nanofiber Membranes Modified by Electrophoretically Deposited TiO2/Graphene Oxide. Polymers 2018, 10, 746.

24. Usha Kiran, N.; Dey, S.; Singh, B.P.; Besra, L. Graphene Coating on Copper by Electrophoretic Deposition for Corrosion Prevention. Coatings 2017, 7, 214. [CrossRef]

25. Vorobyev, A.Y.; Guo, C. Femtosecond laser nanostructuring of metals. Opt. Express 2006, 14, $2164-2169$. [CrossRef] [PubMed]

26. Reg, Y.; Kägeler, C.; Schmidt, M. Experimental studies on effects at micro-structuring of highly reflecting metals using nano- and picosecond-lasers. Phys. Procedia 2010, 5, 245-253. [CrossRef]

27. Rui, Z.; Shengdong, L.; Ye, D.; Huan, Y.; Kenny Ong Yong, K.; Minghui, H. Enhancement of laser ablation via interacting spatial double-pulse effect. Opto. Electron. Adv. 2018, 1, 180014. [CrossRef]

28. Khew, S.Y.; Tan, C.F.; Yan, H.; Lin, S.; Thian, E.S.; Zhou, R.; Hong, M. Nanosecond laser ablation for enhanced adhesion of $\mathrm{CuO}$ nanowires on copper substrate and its application for oil-water separation. Appl. Surf. Sci. 2019, 465, 995-1002. [CrossRef] 
29. Tian, X.; Jokinen, V.; Li, J.; Sainio, J.; Ras, R.H. Unusual Dual Superlyophobic Surfaces in Oil-Water Systems: The Design Principles. Adv. Mater. 2016, 28, 10652-10658. [CrossRef] [PubMed]

30. Yong, J.; Chen, F.; Yang, Q.; Zhang, D.; Farooq, U.; Du, G.; Hou, X. Bioinspired underwater superoleophobic surface with ultralow oil-adhesion achieved by femtosecond laser microfabrication. J. Mater. Chem. 2014, 2, 8790-8795. [CrossRef]

31. Wang, B.; Liang, W.X.; Guo, Z.G.; Liu, W.M. Biomimetic super-lyophobic and super-lyophilic materials applied for oil/water separation: A new strategy beyond nature. Chem. Soc. Rev. 2015, 44, 336-361. [CrossRef] [PubMed]

32. Zhou, R.; Lin, S.; Shen, F.; Khew, S.Y.; Hong, M. A universal copper mesh with on-demand wettability fabricated by pulsed laser ablation for oil/water separation. Surf. Coat. Technol. 2018, 348, 73-80. [CrossRef]

33. Liu, W.Y.; Sun, L.Y.; Wu, R.M.; Chen, Y.; Liu, Y.J. Effects of acid concentration on the superhydrophobic surface on aluminum alloy by etching and PP-coating. Adv. Mater. Res.-Switz. 2013, 763, 49-52. [CrossRef]

2019 by the authors. Licensee MDPI, Basel, Switzerland. This article is an open access article distributed under the terms and conditions of the Creative Commons Attribution (CC BY) license (http://creativecommons.org/licenses/by/4.0/). 